\title{
Asian summer monsoon onset barrier and its formation mechanism
}

\author{
Boqi Liu $\cdot$ Yimin Liu $\cdot$ Guoxiong Wu $\cdot$ Jinghui Yan · \\ Jinhai He $\cdot$ Suling Ren
}

Received: 6 April 2014 / Accepted: 10 August 2014 / Published online: 24 August 2014

(C) The Author(s) 2014. This article is published with open access at Springerlink.com

\begin{abstract}
The onset process of Asian summer monsoon (ASM) is investigated based on diagnostic analysis of observations of precipitation and synoptic circulation. Results show that after the ASM commences over the eastern Bay of Bengal (BOB) around early May, the onset can propagate eastwards towards the South China Sea and western Pacific but is blocked on its westward propagation along the eastern coast of India. This blocking, termed the "monsoon onset barrier (MOB)", presents a Gill-type circulation response to the latent heating released by $\mathrm{BOB}$ monsoon convection. This convective condensation heating generates summertime (wintertime) vertical easterly (westerly) shear to its east (west) and facilitates air ascent (descent). The convection then propagates eastward but gets trapped on its westward path. To the east of the central $\mathrm{BOB}$, the surface air temperature (SAT) cools faster than the underlying sea surface temperature (SST) due to monsoon onset. Thus more sensible heat flux supports the onset convection to propagate eastward. To the west of the central BOB, however, the land surface sensible heating over the Indian Peninsula is strengthened by the enhanced anticyclone circulation and air descent induced by the BOB monsoon heating. The strengthened upstream warm horizontal
\end{abstract}

B. Liu $\cdot$ Y. Liu $(\varangle) \cdot$ G. Wu $\cdot$ J. He $\cdot$ S. Ren

State Key Lab of Atmospheric Sciences and Geophysical Fluid Dynamics (LASG), Institute of Atmospheric Physics, Chinese Academy of Sciences, Beijing 100029, China

e-mail: lym@lasg.iap.ac.cn

B. Liu $\cdot$ J. He

Key Laboratory of Meteorological Disaster (Nanjing University of Information Science and Technology), Ministry of Education, Nanjing 210044, China

J. Yan $\cdot$ S. Ren

China Meteorological Administration, Beijing 100081, China advection then produces a warm SAT center over the MOB region, which together with the in situ cooled SST reduces the surface sensible heating and atmospheric available potential energy to prevent the occurrence of free convection. Therefore, it is the change in both large-scale circulation and air-sea interaction due to BOB summer monsoon onset that contributes to the MOB formation.

Keywords Monsoon onset barrier - Bay of Bengal summer monsoon · Gill-type response $\cdot$ Air-sea interaction

\section{Introduction}

Monsoon occurs as a consequence of the seasonal reversal of circulation induced by an atmospheric response to the seasonal transition of land-sea thermal contrast. Monsoon onset is characterized by rapid changes in the prevailing wind direction and rainfall intensity. However, rainfall is both the result of, and a driving force for, the atmospheric circulation (Eady 1950). The atmospheric response and feedback to the huge latent heating of monsoon convection makes the monsoon onset process highly complex. The evolution of Asian summer monsoon (ASM) onset, which is accompanied by an abrupt enhancement of atmospheric energy and the water cycle, takes approximately 1 month (Wu et al. 2013) and has great impact on society and economic growth in Asian countries.

The ASM onset process is characterized by three successive phases: onset begins over the southeastern Bay of Bengal (BOB), followed by onset over the South China Sea (SCS), and finally over India (Wu and Zhang 1998; Wang and Lin 2002; Mao et al. 2003; Mao and Wu 2007; Yang et al. 2012). The BOB summer monsoon onset is associated with an overturning of the meridional air temperature 
gradient (MTG) in the mid-upper troposphere (Mao and $\mathrm{Wu}$ 2007). In the lower troposphere, the development of monsoon onset vortex (MOV) in early May over the BOB plays an important role in the onset (Lau et al. 1998; Liu et al. 2002; Vinayachandran et al. 2007). It has been demonstrated that MOV formation and development are dominated by the effects of local air-sea interaction (Wu et al. 2011, 2012a), barotropic and baroclinic instability (e.g., Krishnamurti et al. 1981; Mak and Kao 1982; Mao and $\mathrm{Wu} 2011$ ), and the pumping effect in the upper troposphere (Liu et al. 2013). All the above factors are strongly influenced by the Tibetan Plateau forcing (Wu et al. 2011, 2012a).

The SCS summer monsoon onset is characterized by multi-scale activities (Ding and Chan 2005; Wang et al. 2009a). The mechanism for the establishment of SCS summer monsoon can be classified into two categories: one is atmospheric internal variability, including the local intraseasonal oscillation (Chen and Chen 1995; Zhou and Chan 2005; Wu 2010) and effect of neighboring weather systems (Chan et al. 2000; Xu and Chan 2001; Liu et al. 2002; Tong et al. 2009); the other is external forcing, such as the thermal and mechanical effects of local orography (Qian et al. 2001; Xie et al. 2003; Xu et al. 2008) and air-sea interaction (Zhou and Chan 2007).

For the Indian summer monsoon onset process, there are traditionally two different viewpoints. One considers Indian summer monsoon onset as the seasonal northward movement of the Intertropical Convergence Zone (ITCZ) (e.g., Saha and Saha 1980; Srinivasan et al. 1993; Gadgil and Sajani 1998; Gadgil 2003). The other treats the onset as a westward propagation of the ASM onset process, which commences over the eastern BOB (e.g., Tao and Chen 1987; Tanaka 1992). It has also been proposed that Indian summer monsoon onset is determined by the arrival of the active phase of 30-60-day intraseasonal oscillation (ISO) at the Indian Peninsula (Goswami and Mohan 2001; Goswami 2005). In addition, the mechanical and thermal effects of the Tibetan Plateau on ASM onset have been highlighted by many researchers (Tao and Chen 1987; Li and Yanai 1996; Hung and Yanai 2004; Hung et al. 2004; Abe et al. 2013). In particular, the significant impact of the surface sensible heat driven air-pump (SHAP) of the Iranian and Tibetan plateaus on ASM onset and evolution has also been emphasized (Wu et al. 2007, 2012b).

Despite remarkable accomplishments achieved in the past decades concerning ASM dynamics, many questions remain unanswered. One example of an area yielding many such questions is the study of the propagation of ASM onset. It is still unclear how ASM onset evolves and what is the controlling mechanism. By analyzing ASM onset isochrones based on scarce data, Tao and Chen (1987) suggested that the earliest ASM onset is over the SCS in mid May. It then propagates westward gradually and eventually reaches the Indian subcontinent. Other earlier studies proposed that after the commencement of ASM over the BOB, ASM rainfall can propagate eastward and westward concurrently (Lau and Yang 1997; Webster et al. 1998; Wang and LinHo 2002). In contrast, based on an analysis of ECMWF reanalysis data, Wu and Zhang (1998) proposed that ASM onset begins over the BOB in early May, then extends eastward to the SCS in mid May, but it cannot propagate westward directly to India. Based on the NCEP/NCAR reanalysis products (Kalnay et al. 1996) and CMAP rainfall data (Xie and Arkin 1997), Yan (2005) further revealed that the westward propagation of ASM onset gets trapped over the western coast of the $\mathrm{BOB}$, which is termed the "monsoon onset barrier" (MOB) in this study. However, the mechanism responsible for the formation of the MOB remains unclear.

The objective of this study is to investigate the general characteristics of the MOB based on rainfall and reanalysis datasets, and explore the possible mechanism for its formation. The remainder of the paper is organized as follows. Section 2 describes the data and method applied. The propagation of ASM onset based on different precipitation data products is investigated in Sect. 3. Section 4 explores the possible mechanism for the MOB formation. Finally, a summary and discussion of the key findings are presented in Sect. 5.

\section{Data and method}

\subsection{Data description}

To reduce the uncertainty in any individual dataset, three types of precipitation data, i.e., the CPC Merged Analysis of Precipitation (CMAP) (Xie and Arkin 1997) from 1979 to 2010 provided by the National Oceanic and Atmospheric Administration (NOAA), version 1.2 of the Global Precipitation Climatology Project (GPCP) one-degree daily precipitation records (Huffman et al. 2001) from 1997 to 2010, and the Tropical Rainfall Measurement Mission Project (TRMM) daily rainfall production (3B42 Version7) from 1998 to 2010 provided by the National Aeronautics and Space Administration (NASA), are used to depict the MOB. The horizontal resolutions of the CMAP, GPCP and TRMM datasets are $2.5^{\circ} \times 2.5^{\circ}, 1.0^{\circ} \times 1.0^{\circ}$, and $0.25^{\circ} \times 0.25^{\circ}$, respectively. The 3-D wind field, air temperature on standard isobars and at 2-m height, total cloud cover and surface heat flux, with a horizontal resolution of $1.5^{\circ} \times 1.5^{\circ}$, are extracted from the ERA-Interim reanalysis data from 1979 to 2010 (Dee et al. 2011) to describe the ASM onset characteristics. The Outgoing Longwave Radiation (OLR, Liebmann and Smith 1996) from 1979 to 2010 is provided by NOAA with a horizontal resolution 
of $2.5^{\circ} \times 2.5^{\circ}$. Over the ocean surface, daily sensible heat flux, sea surface temperature (SST) and surface air temperature (SAT) with a horizontal resolution of $1^{\circ} \times 1^{\circ}$ from 1985 to 2010 are obtained from the Objectively Analyzed Air-Sea Fluxes (OAFlux), which is archived by the Woods Hole Oceanographic Institution (WHOI) Cooperative Institute for Climate and Ocean Research (CICOR).

\subsection{Method}

In this study, both the changes in circulation and precipitation are used to define ASM onset. As proposed by Mao et al. (2003, 2007), ASM onset is identified as the time when the ridge surface of the subtropical anticyclone starts to tilt northward towards the warm land area from winter to summer. Based on the thermal wind relationship, this tilting process can be expressed by the reversal of the MTG in the upper troposphere (500-200 hPa), implying the change in sign of $\partial u / \partial z$, or $-\partial T / \partial y$, along the ridge surface. This criterion is actually equivalent to the monsoon onset indices proposed by Webster and Yang (1992) based on the change in vertical shear of zonal wind $(\partial u / \partial z)$ and by Li and Yanai (1996) according to the change in meridional temperature difference between $5^{\circ} \mathrm{N}$ and $30^{\circ} \mathrm{N}(-\partial T / \partial y)$. The MTG definition reflects the essence of the onset process of the BOB, SCS, and Indian summer monsoons.

Precipitation is an important element related to ASM onset. ASM onset can also be determined when a dramatic increase in rainfall occurs (Yoshino 1966; Wang 2006), with a threshold of greater than $5 \mathrm{~mm} \mathrm{day}^{-1}$ over ocean and $3 \mathrm{~mm} \mathrm{day}^{-1}$ over land. Moreover, since the heavy precipitation is usually accompanied by an evident change in wind direction, it is necessary to take the wind direction change into account when identifying ASM onset. Here, the wind direction $(\theta)$ is as usual defined as

$\theta= \begin{cases}0^{\circ} & \text { if } u=0, v<0 \\ 270^{\circ}-\tan ^{-1}(v / u) & \text { if } u>0 \\ 180^{\circ} & \text { if } u=0, v>0 \\ 90^{\circ}-\tan ^{-1}(v / u) & \text { if } u<0 .\end{cases}$

in which $0^{\circ}, 90^{\circ}, 180^{\circ}$ and $270^{\circ}$ represent northerly, easterly, southerly and westerly wind, respectively. And the deviation of wind direction on each day $\left(\theta_{t}\right)$ from the mean value in January $\left(\overline{\theta_{1}}\right)$ is treated as the wind direction change $(\Delta \theta)$, i.e.,

$\Delta \theta= \begin{cases}\left(\theta_{t}-\overline{\theta_{1}}\right)-360^{\circ}, & \text { if } \theta_{\mathrm{t}}-\overline{\theta_{1}}>180^{\circ} ; \\ \left|\left(\theta_{t}-\overline{\theta_{1}}\right)+360^{\circ}\right|, & \text { if } \theta_{\mathrm{t}}-\overline{\theta_{1}}<-180^{\circ} .\end{cases}$

The summer monsoon onset is marked by a greater than $100^{\circ}$ change of surface wind direction at $10-\mathrm{m}$ height $(\mathrm{Wu}$ et al. 2013). The thresholds of $100^{\circ}, 120^{\circ}$ and $140^{\circ}$ have been tested to determine ASM onset, and the results show no significant difference. One reason for choosing the
Table 1 Linear correlation coefficients of onset dates defined by the ASMOC in this study with others over the BOB, SCS, and India

\section{$B O B$}

U850 (Mao and Wu 2007)

0.892

OLR (Mao and Wu 2007)

0.635

MTG (Mao and Wu 2007)

0.804

SCS

Wang et al. (2004)

0.504

Wang and Wu (1997)

0.699

Tian and Wang (2010)

0.557

India

Ananthakkrishnan and Soman (1988)

0.665

Wang and Wu (1997)

0.699

Taniguchi and Koike (2006) $\quad 0.739$

Xavier et al. (2007) $\quad 0.678$

Wang et al. (2009b) $\quad 0.734$

Prasad and Hayashi (2005)

0.739

All values have passed the $99 \%$ confidence level

threshold of $100^{\circ}$ is that the wind direction change during ASM onset in spring is smaller than that in July (usually $\left.120^{\circ}\right)$. The other reason is that the wind direction change is less than $120^{\circ}$ over the northeastern BOB $\left(15^{\circ}-23^{\circ} \mathrm{N}\right)$ due to the influence of the Indo-Burma trough.

Therefore, the ASM onset date on each grid can be defined as the day when the following ASM onset criteria (ASMOC) are satisfied:

1. The upper tropospheric (500-200 hPa) MTG changes from negative to positive and remains positive for more than 10 days;

2. The wind direction change at $10-\mathrm{m}$ height is greater than $100^{\circ}$;

3. The rainfall is steadily greater than $5 \mathrm{~mm} \mathrm{day}^{-1}$ over the ocean and $3 \mathrm{~mm}$ day $^{-1}$ over the land.

If the area-averaged $\mathrm{MTG}$, wind direction change and rainfall over the $\mathrm{BOB}\left(5^{\circ}-15^{\circ} \mathrm{N}, 85^{\circ}-100^{\circ} \mathrm{E}\right)$, the $\mathrm{SCS}\left(5^{\circ}-\right.$ $\left.20^{\circ} \mathrm{N}, 110^{\circ}-120^{\circ} \mathrm{E}\right)$ and India $\left(10^{\circ}-20^{\circ} \mathrm{N}, 60^{\circ}-75^{\circ} \mathrm{E}\right)$ meet the ASMOC, the summer monsoon is considered to commence in those specific regions. The onset dates of summer monsoon over the BOB, the SCS and India defined by the ASMOC are significantly correlated with those defined by other criteria (Table 1), including the zonal wind at $850 \mathrm{hPa}$ (Wang et al. 2004, 2009b; Tian and Wang 2010), the OLR or precipitation (Ananthakkrishnan and Soman 1988; Wang and Wu 1997), the MTG in the middle and upper troposphere (Webster et al. 1998; Mao and Wu 2007), and the vertically integrated diabatic heating (Xavier et al. 2007) or water vapor (Taniguchi and Koike 2006; Prasad and Hayashi 2005). The climatology obtained by arithmetically 

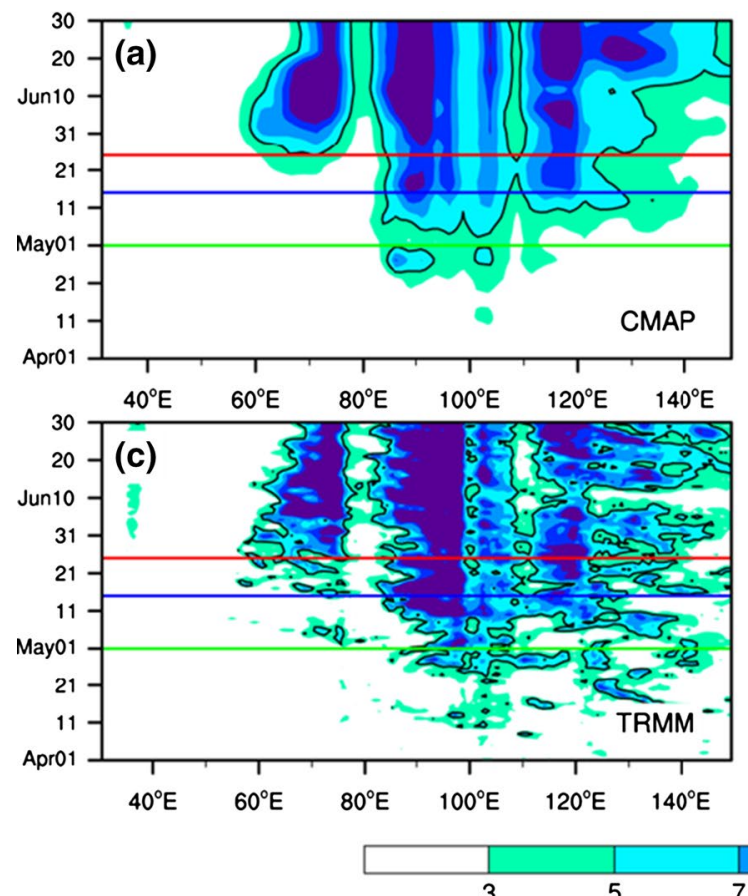
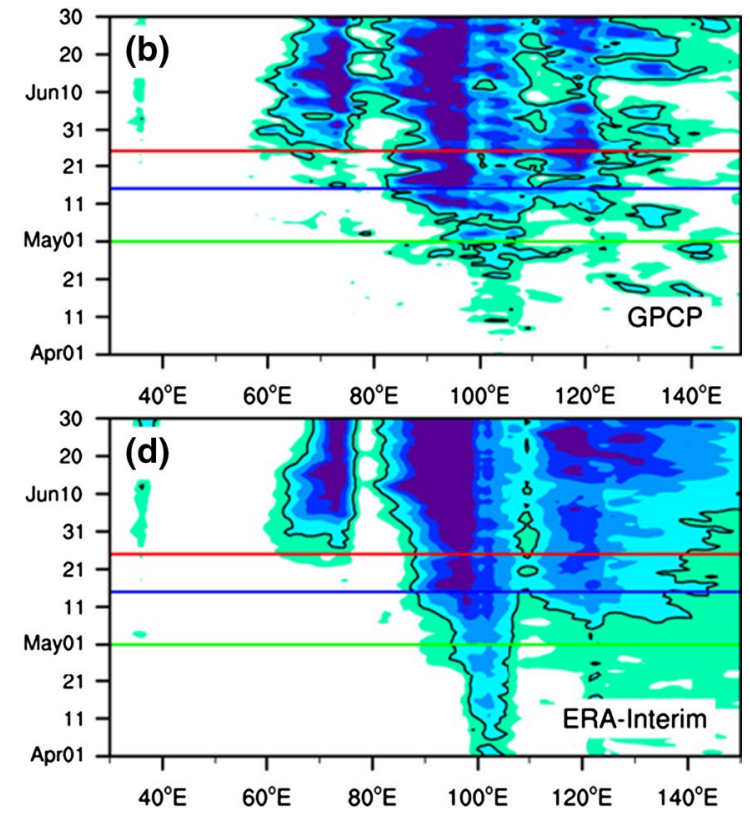

11
Fig. 1 Evolutions of daily mean precipitation derived from a CMAP, b GPCP, c TRMM and d ERA-Interim averaged over $10^{\circ}-20^{\circ} \mathrm{N}$ for the period 1 April-30 June. The contour interval is $2 \mathrm{~mm} \mathrm{day}^{-1}$, and solid black curves indicate the $5 \mathrm{~mm}$ day $^{-1}$ contour. Red, blue and green bold lines denote, respectively, the onset dates of summer monsoon over the BOB $\left(5^{\circ}-15^{\circ} \mathrm{N}, 85^{\circ}-100^{\circ} \mathrm{E}\right)$, SCS $\left(10^{\circ}-20^{\circ} \mathrm{N}, 110^{\circ}-\right.$ $\left.120^{\circ} \mathrm{E}\right)$, and India $\left(10^{\circ}-20^{\circ} \mathrm{N}, 60^{\circ}-75^{\circ} \mathrm{E}\right)$ regions defined by the MTG index, as shown in Fig. 2a

onset process well. Along the latitudinal zone between $10^{\circ} \mathrm{N}$ and $20^{\circ} \mathrm{N}$, rainfall intensification first occurs over the BOB from late April to early May, and then expands eastward with its maximum reaching the SCS around mid May. Over the Arabian Sea and Indian Peninsula, however, no westward propagation of monsoon rainfall is found after the BOB summer monsoon onset. It is not until the end of May and early June that the rainfall over the Arabian Sea and Indian subcontinent enhances to greater than 5 or $3 \mathrm{~mm}$ day $^{-1}$, representing the Indian summer monsoon onset. The three-phase feature of ASM onset, as first revealed in a case study by Wu and Zhang (1998), can be identified clearly from the climatological means based on different data sets. Since the spatial and temporal distributions of CMAP rainfall are similar to their counterparts from satellite observations and reanalysis data, and since the CMAP data set is high quality and has a long history, it is appropriate to use CMAP precipitation to study ASM onset. Hereafter, we adopt CMAP precipitation to define the rainfall criterion for ASM onset.

According to the MTG summer monsoon onset criteria, climatologically the summer monsoon onset times over the $\mathrm{BOB}$, the SCS, and the Indian subcontinent are determined as early May, mid May, and late May, respectively (Fig. 2a). These are also plotted in Fig. 1 for comparison purposes. The three-phase monsoon onset identified by the 

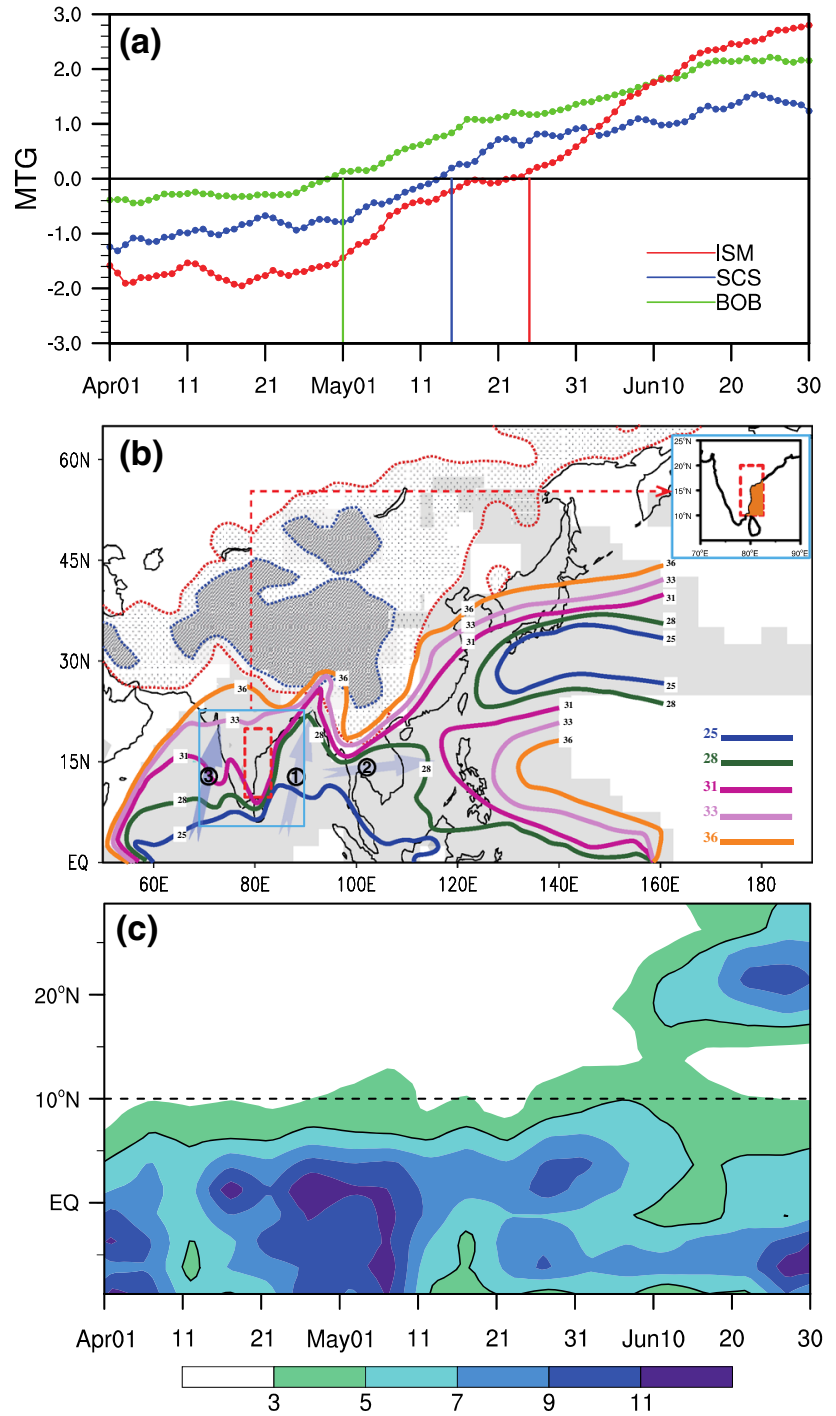

Fig. 2 a Time series of the MTG $\left(10^{-6} \mathrm{~K} \mathrm{~m}^{-1}\right)$ averaged over the BOB $\left(5^{\circ}-15^{\circ} \mathrm{N}, 85^{\circ}-100^{\circ} \mathrm{E}\right)$, SCS $\left(10^{\circ}-20^{\circ} \mathrm{N}, 110^{\circ}-120^{\circ} \mathrm{E}\right)$, and India $\left(10^{\circ}-20^{\circ} \mathrm{N}, 60^{\circ}-75^{\circ} \mathrm{E}\right)$. Green, blue and red bold lines denote the onset date of summer monsoon over the BOB, SCS, and India, respectively. b The climatological pentad-isochrones indicating the onset process of Asian summer monsoon. The arrows with the circled numbers 1, 2 and 3 represent the onset phases over the BOB, SCS and India. The area encircled by red and blue dot lines represents the topography greater than 500 and $1,500 \mathrm{~m}$, respectively. Orange shading within the definition region (box bounded between $78^{\circ} \mathrm{E}$ and $82.5^{\circ} \mathrm{E}$ and between $10^{\circ} \mathrm{N}$ and $20^{\circ} \mathrm{N}$ ) over the eastern coastal waters of Indian Peninsula in the inserted map denotes the monsoon onset barrier (MOB) region. The gray-filled area represents the Asian summer monsoon region where the ASMOC are satisfied (see text for details). c Time-latitude crossing section of CMAP rainfall $\left(\mathrm{mm} \mathrm{day}^{-1}\right)$ from April to June and averaged between $78^{\circ} \mathrm{E}$ and $82.5^{\circ} \mathrm{E}$ in which the MOB is located, solid black curves indicate the $5 \mathrm{~mm}$ day $^{-1}$ contours

precipitation is comparative to that depicted by the MTG, and is prominent based on both the MTG analysis and the precipitation.
The ASM onset process can be depicted more clearly by analyzing its climatological daily or pentad isochrones (Tao and Chen 1987; Lau and Yang 1997; Webster et al. 1998; Wang and LinHo 2002). Due to the limitation of available data, as well as the different onset criteria and diversity of datasets used in various studies, remarkable discrepancies exist in previous work with respect to the isochrones of ASM onset. Most of these isochrones of summer monsoon onset are based on the seasonal rainfall variation (Tao and Chen 1987; Lau and Yang 1997; Wang and LinHo 2002). However, since ASM onset is accompanied by a seasonal reversal of the prevailing wind direction, it is insufficient to determine ASM onset based solely on the rainfall criterion without considering the change in wind direction. Accordingly, it is more appropriate to identify ASM onset in light of the seasonal transition of the MTG, the wind direction change, and the rainfall variation.

Here, the ASM onset isochrones are calculated over the ASM region based on the ASMOC described in Sect. 2. The ASM region is identified as the area where all three of the onset criteria are satisfied for at least one pentad in boreal summer. The results shown in Fig. $2 b$ demonstrate that ASM starts with BOB summer monsoon onset at Pentad 25 (1-5 May). It then expands eastwards, crosses the Indochina Peninsula, and reaches the SCS at Pentad 28 (16-20 May), corresponding to the SCS summer monsoon onset. However, after ASM onset is established over the BOB around early May, it cannot propagate westward to reach India and the Arabian Sea directly. In other words, the westward propagation of ASM onset is blocked near the western coast of the $\mathrm{BOB}$, forming a MOB in situ (Fig. 2b). Here the MOB region is defined as the ocean portion in the definition region which is located in the western coast of the BOB and the eastern coastal waters of Indian Peninsula bounded between $78^{\circ} \mathrm{E}$ and $82.5^{\circ} \mathrm{E}$ and between $10^{\circ} \mathrm{N}$ and $20^{\circ} \mathrm{N}$. In this region the ASMOC is not satisfied and the tropical rainfall greater than $5 \mathrm{~mm} \mathrm{day}^{-1}$ is limited to the south of $10^{\circ} \mathrm{N}$ from April to early June (Fig. 2c). Because of the existence of MOB, the summer monsoon onset process over the Arabian Sea/India appears as a rainy belt advancing northward from the equator to the north during Pentads 25-31. The rainy belt reaches the southwestern coast of Indian Peninsula at Pentad 30 (26-30 May), indicating the Indian summer monsoon onset, and by the time the 1-month process of tropical ASM onset has completed.

\section{Possible mechanism for the MOB formation}

Figure $2 b, c$ indicate that the MOB is generated after the BOB summer monsoon onset. To investigate the effect of BOB summer monsoon convection on the MOB formation, we define the pre-onset and post-onset stage as the mean 

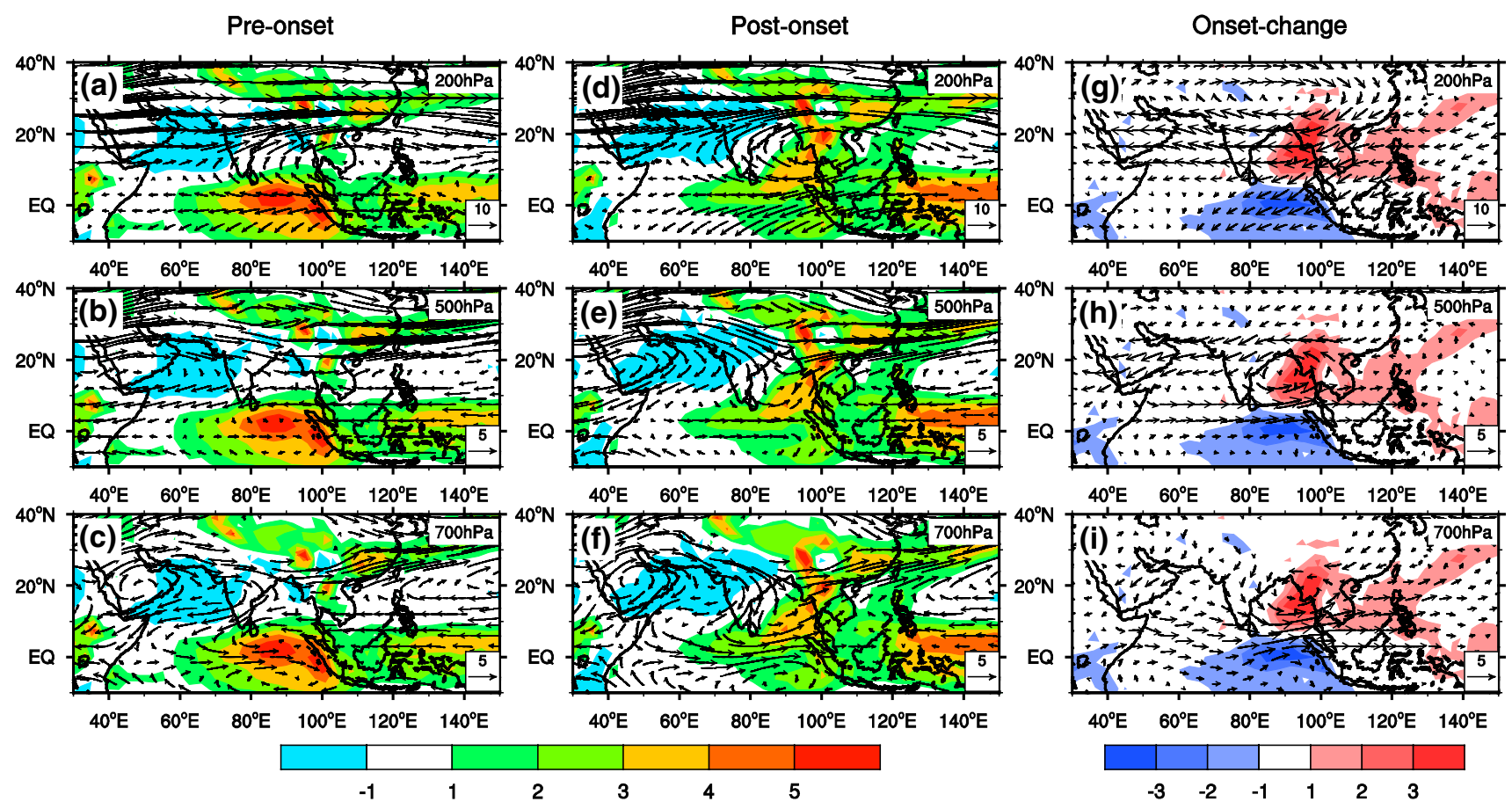

Fig. 3 Horizontal distributions of wind field (vectors) at a, d $200 \mathrm{hPa}$, b, e $500 \mathrm{hPa}$, and c, f $700 \mathrm{hPa}$, and diabatic heating $Q_{1}$ at $400 \mathrm{hPa}$ (shading) in the pre-onset $(\mathbf{a}-\mathbf{c})$ and post-onset $(\mathbf{d}-\mathbf{f})$ stages of BOB summer monsoon. The onset change of $Q_{1}$ at $400 \mathrm{hPa}$ (shad-

ing) and the wind field (vectors) at 200, 500 and $700 \mathrm{hPa}$ are presented in $(\mathbf{g}-\mathbf{i})$, respectively. Units are $\mathrm{m} \mathrm{s}^{-1}$ for wind and $\mathrm{K} \mathrm{day}^{-1}$ for $Q_{1}$

state from $\mathrm{D}_{-10}$ to $\mathrm{D}_{-1}$ and from $\mathrm{D}_{+1}$ to $\mathrm{D}_{+10}$, respectively. To highlight the effect of $\mathrm{BOB}$ monsoon convection, the onset change is defined as the difference between the postonset and pre-onset stages. This 21-day period centered on the onset day is long enough for Rossby waves to develop but short enough to isolate the onset signal from the more general seasonal evolution. Based on a diagnostic analysis of various elements in different onset stages and their onset changes, the impact of BOB monsoon onset on the local circulation and air-sea interaction can be revealed.

\subsection{Impact of BOB convection on the large-scale atmospheric circulation}

The distribution of diabatic heating in the middle troposphere and the relevant atmospheric circulation at different levels associated with BOB summer monsoon onset are shown in Fig. 3. In the pre-onset stage of BOB summer monsoon, the diabatic heating at $400 \mathrm{hPa}$ released by tropical convection is situated over the southern BOB along the equator (Fig. 3a-c). The only rainfall located from $10^{\circ} \mathrm{N}$ to $20^{\circ} \mathrm{N}$ is the pre-monsoon convection over the Indochina Peninsula, which is generated under the mechanical and thermal forcing of the Tibetan Plateau prior to the BOB summer monsoon onset (Liu et al. 2013). Meanwhile, in the upper troposphere the South Asian high (SAH) settles at $10^{\circ} \mathrm{N}$ with its center over the southern SCS (Fig. 3a), and in the middle and lower troposphere a continuous subtropical anticyclone belt is located along $10^{\circ} \mathrm{N}-20^{\circ} \mathrm{N}$ from Arabian Peninsula to western Pacific (Fig. 3b, c). After the BOB summer monsoon onset in early May, as shown in Fig. 2b, massive diabatic heat release $\left(Q_{1}\right)$ takes place over the northeastern BOB due to the monsoon convection (Fig. 3df); the $\mathrm{SAH}$ at $200 \mathrm{hPa}$ has migrated northwestward over the Indochina Peninsula (Fig. 3d); and a deep trough in the middle and lower troposphere, named the Indo-Burma trough, has established over the northern BOB (Fig. 3e, f). The evolution of circulation during the BOB summer monsoon onset can be further depicted by the onset changes in $Q_{1}$ at $400 \mathrm{hPa}$ and the wind field on different isobaric surfaces (Fig. 3g-i). A meridional dipole pattern of $Q_{1}$ at $400 \mathrm{hPa}$, presenting a positive center over the northern and central east $\mathrm{BOB}$ and a negative one near the equator, implicates the northward migration of monsoon convection over the BOB. As the SAH elongates northwestwards, the onset change of $200-\mathrm{hPa}$ circulation manifests itself as an anticyclone over the Tibetan Plateau to the north of the $Q_{1}$ center over the northeastern BOB (Fig. 3g). In the middle and lower troposphere, a closed cyclone is located over the $\mathrm{BOB}$ at 500 and $700 \mathrm{hPa}$ (Fig. 3h, i), consistent with the formation of the Indo-Burma trough and the splitting of the subtropical anticyclone belt. Apparently, the whole picture 

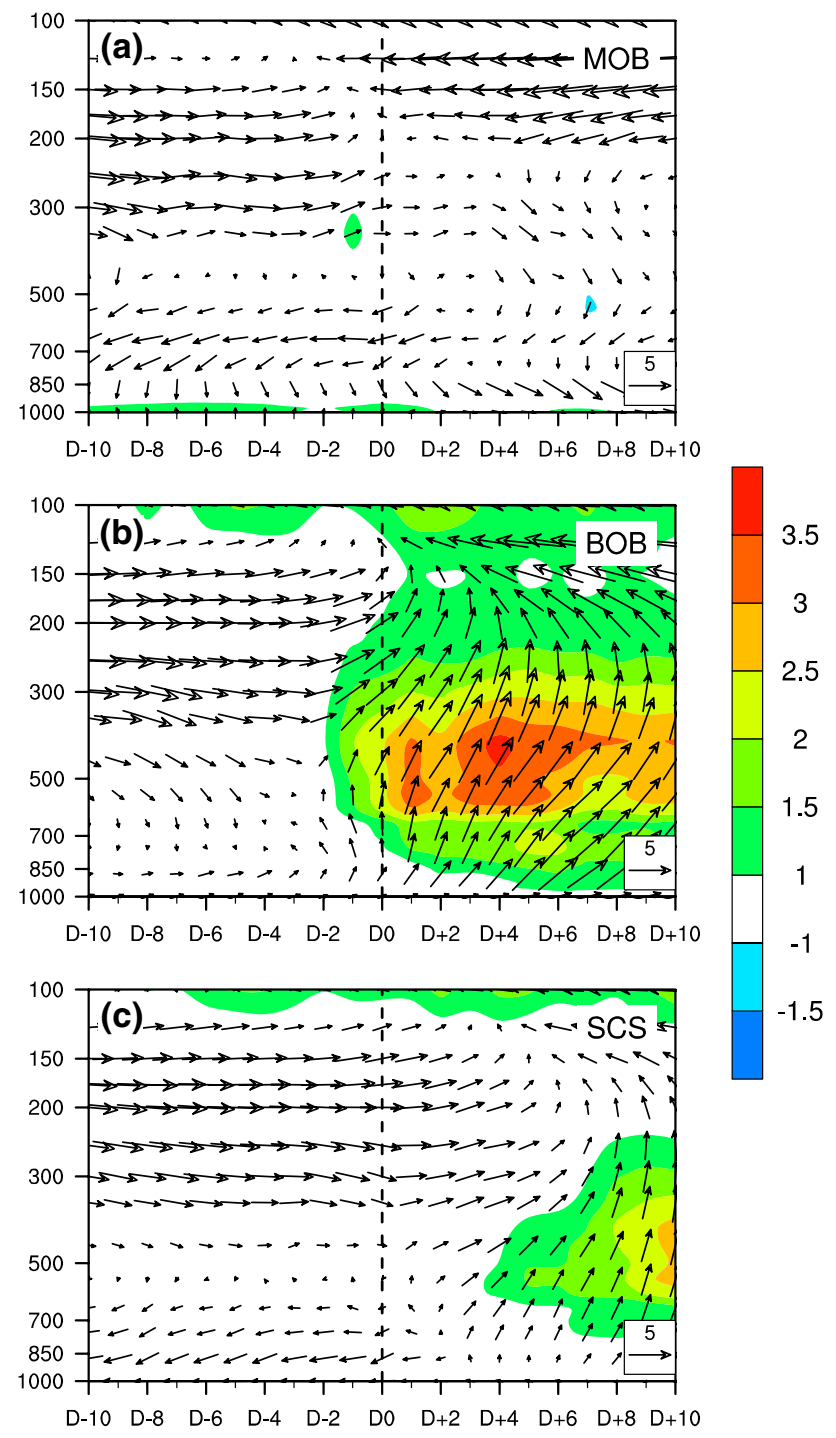

Fig. 4 Pressure-time cross section of local zonal circulation (vectors, $\mathrm{m} \mathrm{s}^{-1}$ ) and $Q_{1}$ (shading; $\mathrm{K} \mathrm{day}^{-1}$ ) over the a MOB region (orange shading shown in Fig. $2 \mathrm{~b})$, b BOB $\left(10^{\circ}-20^{\circ} \mathrm{N}, 90^{\circ}-100^{\circ} \mathrm{E}\right)$, and c $\operatorname{SCS}\left(10^{\circ}-20^{\circ} \mathrm{N}, 110^{\circ}-120^{\circ} \mathrm{E}\right)$

presents a Gill-type circulation response to the BOB monsoon heating (Gill 1980).

The temporal evolutions of vertical motion over different regions are depicted in Fig. 4. As a Gill-type Rossbywave response, a strengthening descent is situated over the MOB region to the west of the BOB monsoon convection (Fig. 4a), especially in the lower troposphere below $500 \mathrm{hPa}$. After the BOB summer monsoon onset, the monsoon convection over the BOB releases a mass of condensation heating after $\mathrm{D}_{0}$. Then the descent over the MOB region, which settles below $500 \mathrm{hPa}$ before $\mathrm{D}_{0}$, is enhanced with the strengthening downward airflow from 500 to $200 \mathrm{hPa}$ after the BOB summer monsoon onset (Fig. 4a). Consequently, the condensation heating released by the
BOB summer monsoon convection is conducive to the formation of the MOB by enhancing the descent to the west of the BOB. In the meantime, a transition from local descent to ascent occurs over the BOB and to its east, accompanied by the remarkable intensified ascent with its maximum near $500 \mathrm{hPa}$ (Fig. 4b, c). Furthermore, the ascent over the SCS develops in the whole troposphere after $\mathrm{D}_{+4}$, implying the incubation of the SCS summer monsoon onset (Fig. 4c).

Figure 4 also shows that the vertical shear of zonal wind is different over the MOB region, BOB and SCS regions during $\mathrm{ASM}$ onset. Before $\mathrm{D}_{0}$, the vertical westerly shear below $200 \mathrm{hPa}$ controls the above three regions. While the vertical westerly shear persists over the MOB region after the BOB summer monsoon onset, it weakens and even reverses to vertical easterly shear over the BOB and SCS after $\mathrm{D}_{0}$ and $\mathrm{D}_{+4}$, respectively. Actually, the vertical shear of zonal wind in the latitudinal band between $10^{\circ} \mathrm{N}$ and $20^{\circ} \mathrm{N}$ is associated with the location of the subtropical anticyclone ridgeline $(u=0)$ at different levels. In the upper troposphere, as the ridgeline migrates gradually northward during the BOB monsoon onset, the easterly is strengthened over the whole ASM region, as shown in Figs. $3 \mathrm{~g}$ and 5a. Note that after the BOB summer monsoon onset, the ridgeline at $200 \mathrm{hPa}$ moves northward slowly to the west of $90^{\circ} \mathrm{E}$, but faster to its east. This is because the $\mathrm{SAH}$ is evidently expanding northeastward due to the latent heat released by monsoon convection over the BOB and SCS (Fig. 3g). In the lower troposphere, however, the ridgeline migration is quite zonal asymmetric (Fig. 5b). Before and after the BOB monsoon onset, the ridgeline remains stable to the west of $90^{\circ} \mathrm{E}$, but migrates southward to its east. The southward withdrawal of the ridgeline over the east is mainly due to the development of cyclonic circulation from the BOB to the SCS, as shown in Fig. 3h, i. Thus, the vertical tilting of the ridgeline between 500 and $200 \mathrm{hPa}$ over the Indian Peninsula remains southward, maintaining the wintertime pattern (Fig. 5c); whereas, it is northward over the Indochina Peninsula (from $100^{\circ} \mathrm{E}$ to $110^{\circ} \mathrm{E}$ ) and has changed to the summertime pattern (Fig. 5d). These changes suggest that, after the BOB summer monsoon onset, vertical westerly shear still maintains over the Indian Peninsula, corresponding to the warm-in-thesouth and cold-in-the-north type pattern associated with winter (Fig. 5e); whereas, strong easterly shear has established to the east of the BOB, implying the development of the warm-in-the-north and cold-in-the-south type pattern, typical of summer, over the eastern ASM area (Fig. 5f). Since a vertical easterly shear strengthens air ascent, the monsoon rainfall expands eastward to the Indochina Peninsula and the SCS. Moreover, based on the thermal wind relationship, the occurrence of vertical easterly shear prompts the MTG reversal from negative to positive and favors the establishment of summer circulation. Consequently the SCS summer monsoon builds up by Pentad 28, following the BOB summer 
Fig. 5 Evolution of the ridgeline from $\mathrm{D}_{-10}$ to $\mathrm{D}_{+10}$ with respect to the BOB summer monsoon onset date at $\mathbf{a}$ $200 \mathrm{hPa}$ and b $500 \mathrm{hPa}$. (c) and (d) respectively present vertical cross sections of the ridgeline of subtropical anticyclone averaged over the "west" and the "east" region, as indicated in (b). Shaded areas in (c) and (d) denote topography. (e) and (f) are the horizontal distribution of the thickness between 500 and $200 \mathrm{hPa}(\mathrm{gpm})$ in the pre-onset and post-onset stage, respectively. The red solid line in (e) and (f) represents the maximum axis of air column thickness
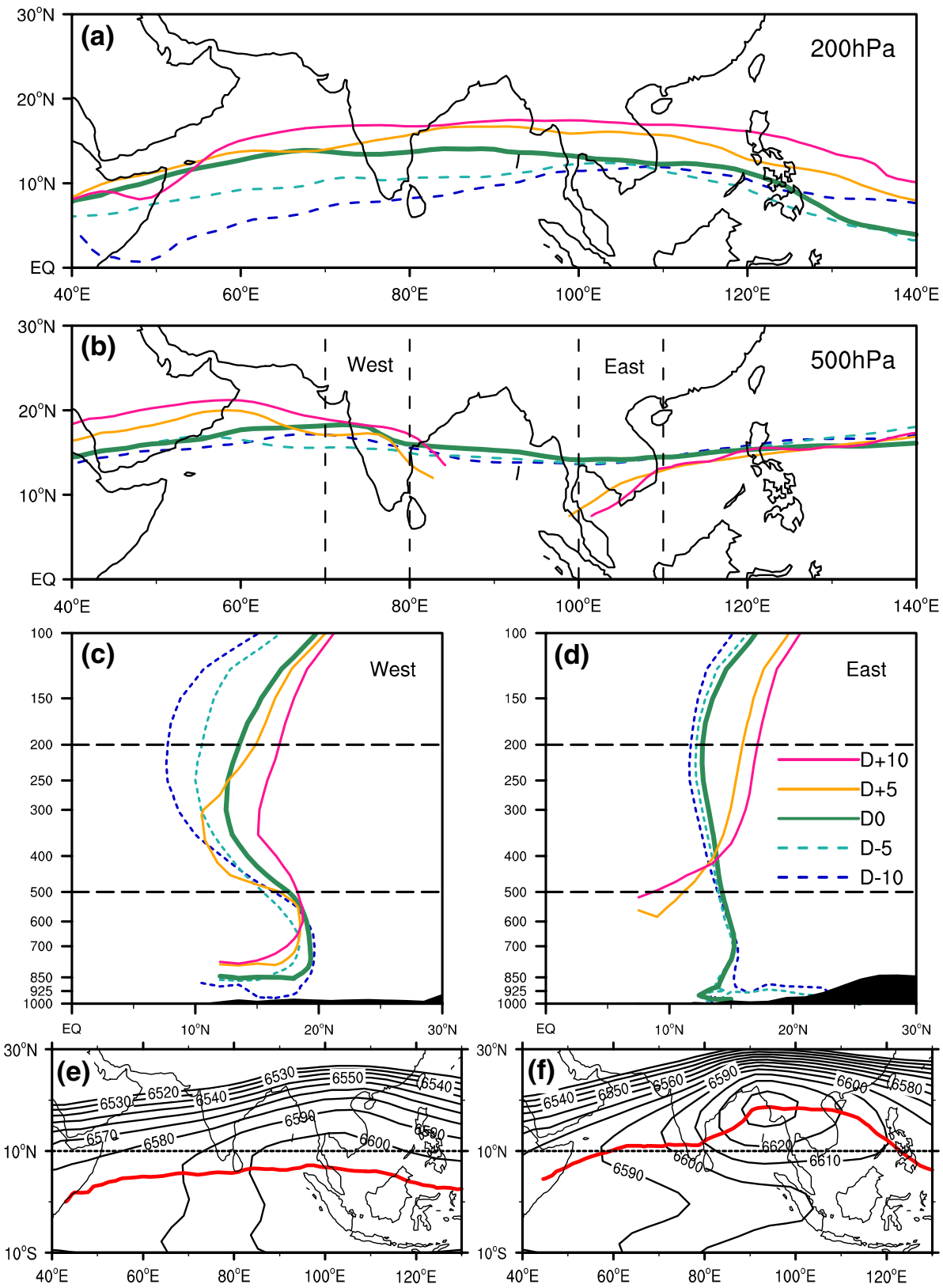

monsoon onset (Fig. 2b). In contrast, the stable vertical westerly shear accompanied by air descent over the MOB region and the Indian Peninsula inhibits the development of monsoon convection. Hence, the westward extension of ASM onset is blocked.

\subsection{Onset changes of thermal structure in the lower troposphere}

As shown in Figs. 1 and 2, the MOB manifests itself as suppressed monsoon convection over east coastal waters of the Indian Peninsula. Hence, it is necessary to first analyze the thermal status over the MOB region to check the atmospheric convective instability. Generally, the spatial distribution of convective available potential energy (CAPE) is used to identify the regions where the atmosphere is convectively unstable, and it determines the potential of deep convection.

However, a high value of CAPE does not necessarily result in strong convection (e.g., Thompson et al. 1979; McBride and Frank 1999; Sobel et al. 2004; Yano and Emanuel 1991), as the simulated air parcel needs to overcome a usually stable layer between the surface and the level of free convection (LFC). The intensity of this stable layer is identified by convective inhabitation energy (CINE), which is expressed as

$\mathrm{CINE}=-\int_{P_{S F C}}^{P_{L F C}} R_{d}\left(T_{v e}-T_{v p}\right) d(\ln P)$ 


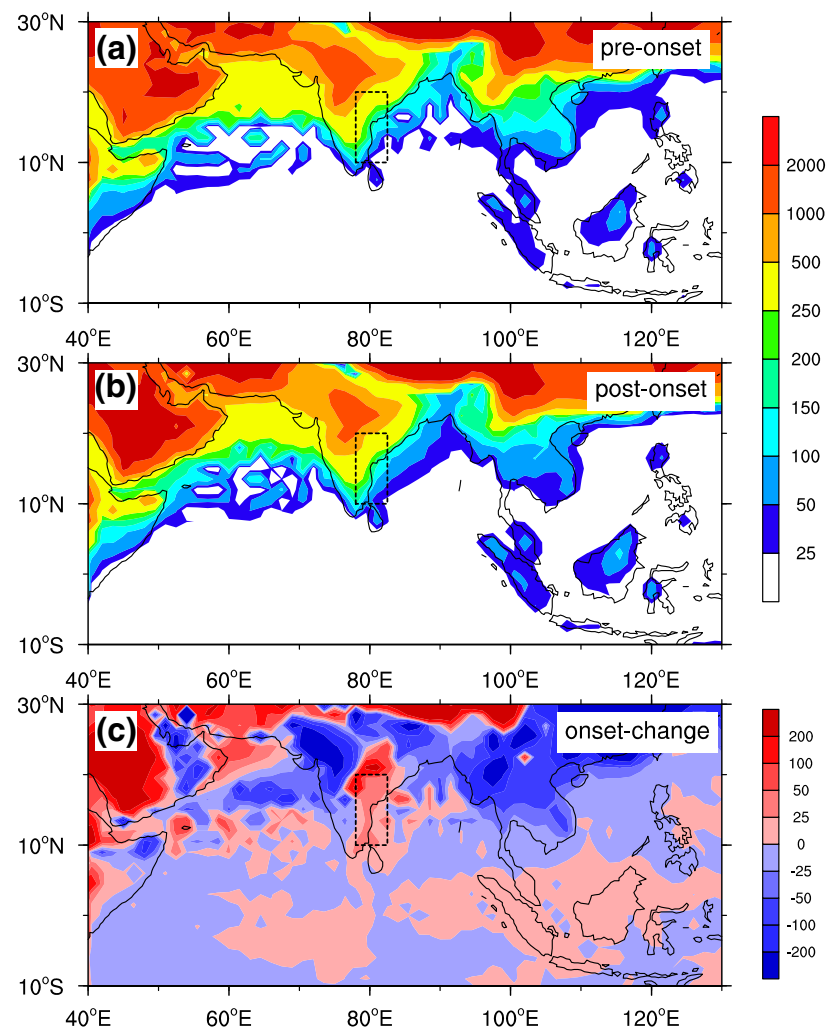

Fig. 6 Horizontal distributions of $\operatorname{CINE}\left(\mathrm{J} \mathrm{kg}^{-1}\right)$ in the a pre-onset and $\mathbf{b}$ post-onset stage. The onset change of CINE is presented in (c). The ocean portion in the box surrounded by dashed lines is the defined MOB region

where $P_{S F C}$ is the surface pressure level $(1,000 \mathrm{hPa}$ in this study); $P_{L F C}$ is the pressure at LFC for a parcel that has risen from $1,000 \mathrm{hPa} ; T_{v e}$ is the virtual temperature of the environment at pressure level $P$ through which the parcel rises; $T_{v p}$ is the virtual temperature of the parcel at pressure level $P$ through which the parcel rises; and $R_{d}$ is the dry gas constant.

As CINE defines the energy of a parcel needed to reach the LFC and therefore to be able to develop convection, CINE describes the limiting factor, which can prevent convection even though very high values of CAPE may exist. Thus, the occurrence of convection is closely associated with the CINE intensity. The larger the CINE, the more difficult it is for the convection to take place.

The horizontal distribution of CINE during the BOB summer monsoon onset is presented in Fig. 6. Before the BOB summer monsoon onset, the CINE is larger than $100 \mathrm{~J} \mathrm{~kg}^{-1}$ over the Indochina Peninsula, and it is greater than $200 \mathrm{~J} \mathrm{~kg}^{-1}$ over the Indian Peninsula. The relatively small CINE over the Indochina Peninsula is related with the local pre-monsoon rainfall. Furthermore, the CINE is very small over the southern BOB and southern Arabian Sea (Fig. 6a), suggesting active convection in the tropics. Subsequently,
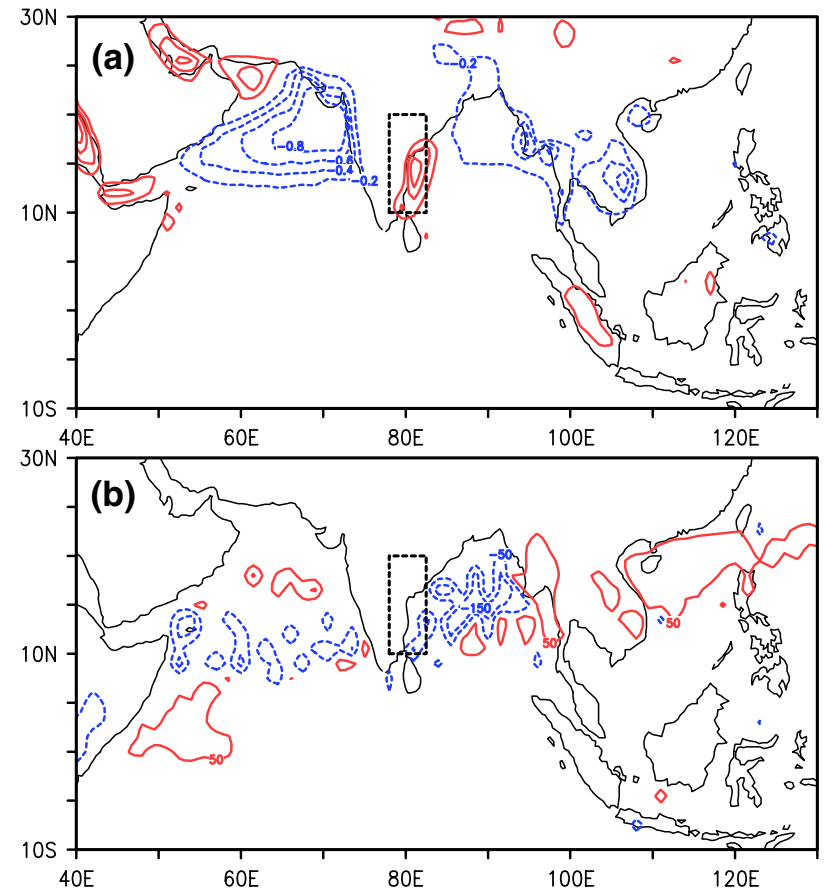

Fig. 7 Onset changes of a the difference between environmental and air parcel virtual temperature $\left(T_{v e}-T_{v a}\right.$, interval is $\left.0.2 \mathrm{~K}\right)$ averaged from 1,000 to $900 \mathrm{hPa}$ and $\mathbf{b}$ the pressure of lifting free convection (interval is $100 \mathrm{hPa}$ ). The ocean portion in the box surrounded by dashed lines is the defined MOB region

monsoon convection develops over the Indochina Peninsula after the BOB summer monsoon onset (Figs. 2b, 4b), accompanied by an obvious in situ decrease in CINE (Fig. 6b). In addition, the CINE starts to diminish over the central and northern Arabian Sea, predicting the independent development of Indian summer monsoon convection (Fig. 2b). Note that the CINE becomes more organized and even larger to the west of the BOB monsoon convection, especially over the MOB region (Fig. 6b). Such evolution of CINE can be presented more evidently in its onset change. Figure $6 \mathrm{c}$ shows that the CINE is increased over the MOB region, but decreased over the eastern BOB after the BOB summer monsoon onset. Over the MOB region, the descent is enhanced (Fig. 4a), leading to a drier and more stable layer and increased CINE in the lower troposphere; whereas, the developed ascent over the eastern BOB is consistent with the less-stable lower troposphere and the decreased CINE. Moreover, the onset change of CINE is determined by variation of the pressure at LFC and the virtual temperature difference between environmental and air parcel $\left(T_{v e}-T_{v p}\right)$ according to Eq. (3). Figure 7a shows that after the BOB summer monsoon onset, the temperature difference between environment and air parcel is increased evidently over the MOB region, but decreased over the eastern $\mathrm{BOB}$. While the pressure at LFC is decreased over the northern BOB 

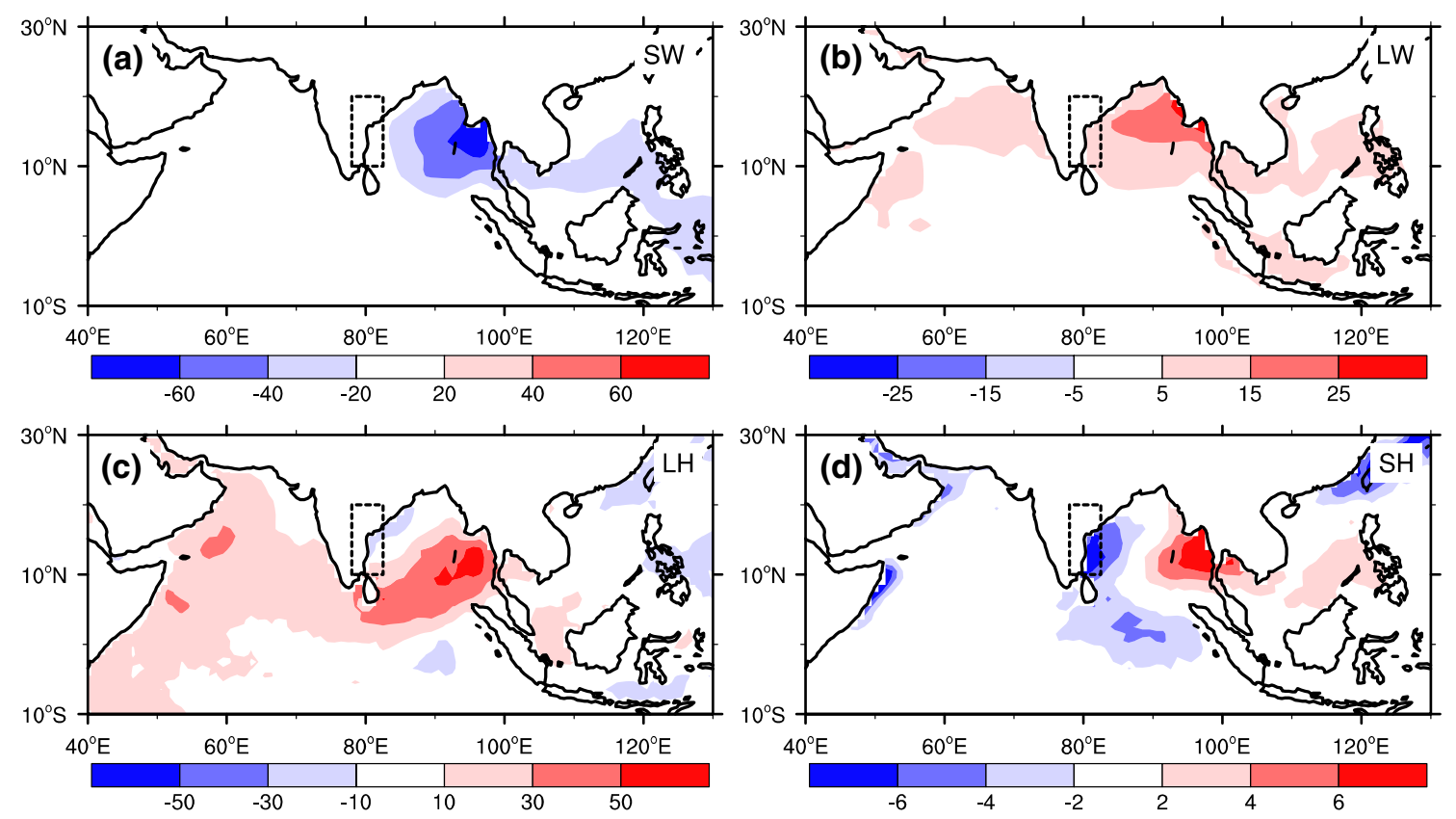

Fig. 8 Onset changes of heating flux $\left(\mathrm{W} \mathrm{m}^{-2}\right)$ at the sea surface: a net downward solar radiation; $\mathbf{b}$ net downward longwave radiation; $\mathbf{c}$ upward latent heating flux; and $\mathbf{d}$ upward sensible heating flux. The radiation and flux are extracted from the ISCCP and OAFlux data-

sets, respectively. Downward is positive in (a) and (b), while upward is positive in (c) and (d). The ocean portion in the box surrounded by dashed lines is the defined MOB region

with its minimum near $90^{\circ} \mathrm{E}$, but increased over the eastern BOB (Fig. 7b). The overlapping in the MOB region between the enhanced CINE and the increased temperature difference (Figs. 6c, 7a) implies that the onset change in temperature difference between environment and air parcel is more important for the increase of CINE over the MOB region after the BOB summer monsoon onset.

The increased onset change in CINE in the MOB region suggests that it requires more energy to uplift the air parcel to the LFC from the surface over the MOB region and the development of monsoon convection becomes more difficult in this region.

\subsection{Impact of BOB convection on air-sea interaction}

Air-sea heat flux is composed of solar radiation, longwave radiation, latent heat flux, and sensible heat flux. Their onset changes are portrayed in Fig. 8. After the BOB summer monsoon onset, due to the abrupt increase in cloud amount over the BOB region, the downward solar radiation is decreased obviously while the downward longwave radiation is increased slightly. Thus the total downward radiation heating received by the sea surface of the $\mathrm{BOB}$ is reduced (Fig. 8a, b). Simultaneously, the upward latent heat flux increases over the BOB (Fig. 8c). Furthermore, the upward sensible heat flux is enhanced over the eastern BOB but weakened over the western BOB, with its minimum over the MOB region (Fig. 8d).

Because of the smaller scale of sensible heat flux, the SST variation is primarily controlled by the onset changes in solar radiation, longwave radiation and latent heat flux. When the BOB summer monsoon builds up, a local cyclone is formed in the lower troposphere over the BOB (Fig. 3i). On one hand, the monsoon convection increases the cloud amount (Fig. 9a, b) to reduce the shortwave solar radiation arriving at the sea surface (Fig. 8a); on the other hand, it strengthens the sea-surface southwesterly, which remarkably increases the latent heat release from the sea surface (Fig. 8c). As a result, the monsoon onset convection over the BOB decreases the SST over most of the BOB by diminishing the shortwave solar radiation and strengthening the sea-surface heat release (Fig. 9c).

Although the sensible heat flux has little influence on SST variation, it is very important for the atmospheric circulation. First, a cloud-free atmosphere does not absorb radiation heating effectively, while the sensible heating from the bottom can generate available potential energy (APE) efficiently in a region $S$ where the heating $Q$ and the temperature $T$ are positively correlated, i.e., $\int_{S}(T Q) d s>0$. Second, it can act as a trigger to release positive CAPE in the atmospheric column by elevating a moist air parcel to the LFC from the underlying surface in the boundary layer. Therefore, as shown in Fig. 8d, the positive sensible heat flux then increases over the eastern BOB where the ASM onset propagates, whereas the negative change of sensible heat develops over the MOB region to inhibit any uplifting 

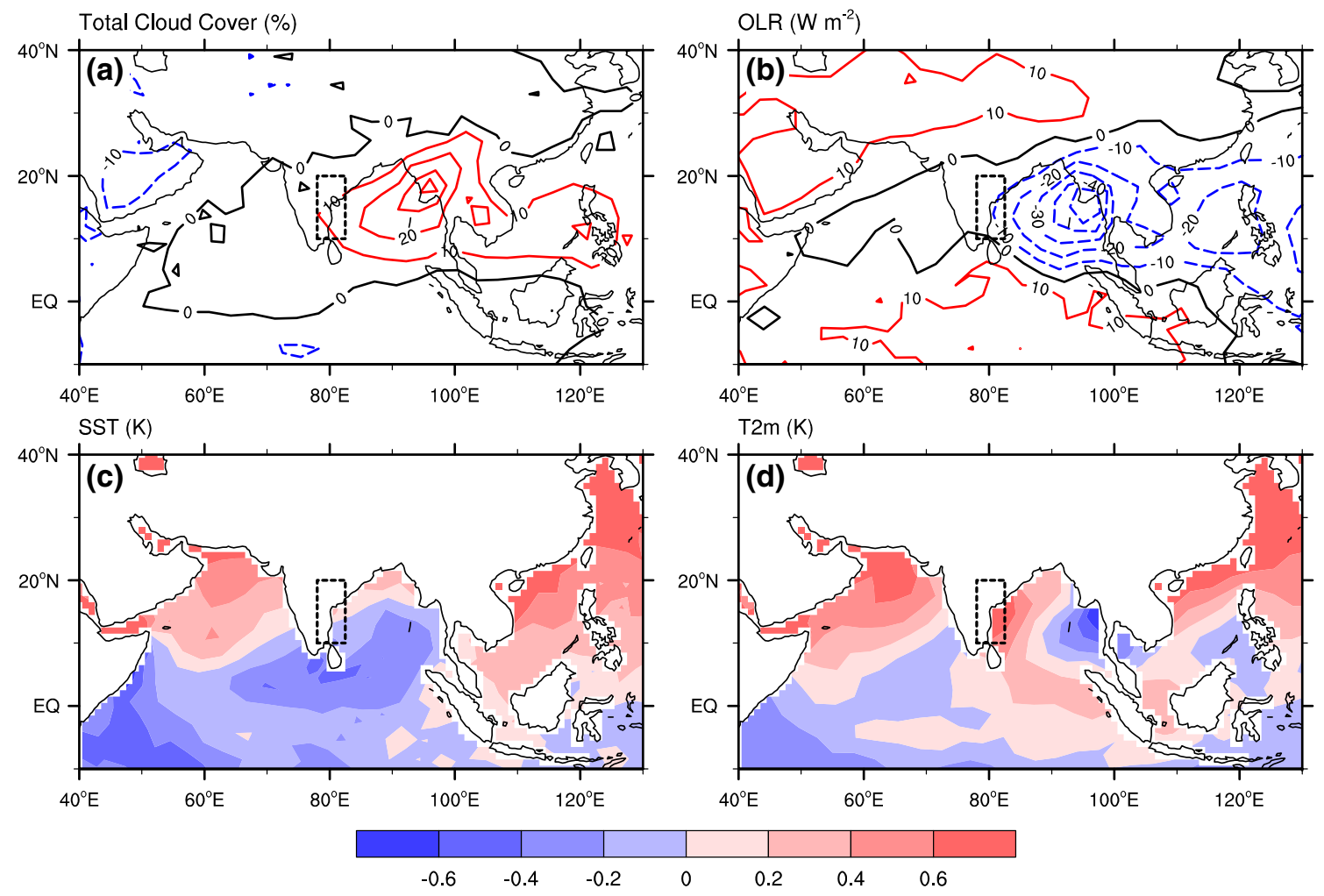

box surrounded by dashed lines is the defined MOB region

of moist parcels, and then the monsoon convection is suppressed. Consequently, the strong negative sensible heat over eastern coastal waters of the Indian Peninsula becomes another factor contributing to the MOB formation after the BOB summer monsoon onset.

More importantly, the polarity of sensible heating over the BOB is ascribed to the difference between SST and SAT (represented by air temperature at 2-m height). Figure 9c, $\mathrm{d}$ implicate that although the SST is cooling over most of the BOB, the SAT variation manifest itself as a very zonal asymmetric distribution, say that the SAT is cooling over the eastern BOB but warming over the western BOB after the BOB summer monsoon onset. Also the warming SAT center is over the MOB region. Actually, after the BOB summer monsoon onset over the eastern BOB, the cooling of SST is weaker than that of SAT, and so positive sensible heating is enhanced. However, over the western BOB, especially over the MOB region, the SST cooling and SAT warming engender negative sensible heating (Fig. 9c, d). Thus the zonal asymmetry of onset change in sea-surface sensible heat flux is primarily ascribed to the SAT variation over the BOB after the BOB summer monsoon onset. In addition to the cooling of SST, the warming of SAT over the MOB region also contributes to the local strong negative sensible heat flux, which supports the MOB genesis.
To investigate the possible reason for the SAT variation before and after the BOB summer monsoon onset, we treat the variables at $925 \mathrm{hPa}$ as proxies for those near the surface because of the similarity of wind and air temperature distributions between $925 \mathrm{hPa}$ and the surface (figure not shown). Their evolution during monsoon onset is shown in Fig. 10. For the 10-day average state the time-dependent terms are weak enough to be ignored and the thermodynamic equation can be written in its stationary form:

$0 \approx \frac{Q_{1}}{c_{p}}-\vec{V} \cdot \nabla T-\omega \frac{\partial T}{\partial p}$,

where $\vec{V}, T$ and $Q_{1}$ are horizontal wind, air temperature, and diabatic heating at $925 \mathrm{hPa}$, respectively; and $c_{p}$ is $1,004 \mathrm{~J} \mathrm{~K}^{-1} \mathrm{~kg}^{-1}$, representing the specific heat of dry air at constant pressure. The balance relationship of Eq. (4) varies from place to place in different episodes of $\mathrm{BOB}$ summer monsoon onset. In the pre-onset stage (Fig. 10ac), over the Arabian Sea and the BOB, the diabatic cooling is primarily balanced by adiabatic warming associated with local subsidence. Meanwhile, the diabatic heating over the Indian Peninsula and Indochina Peninsula is compensated by both cold temperature advection and adiabatic cooling, with the latter prevailing over the former. The 925-hPa air temperature is warm over the Indian Peninsula but cold 

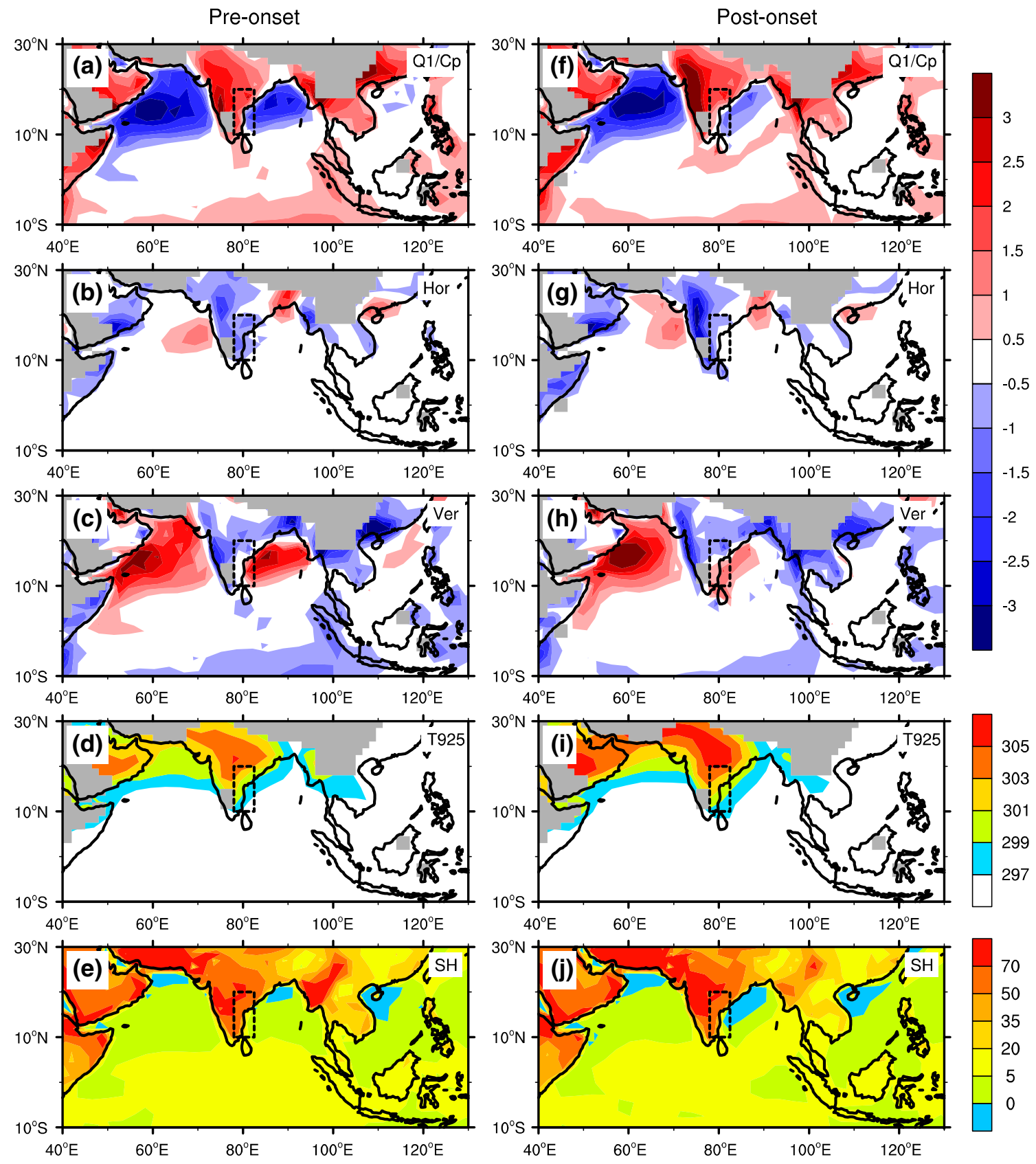

Fig. 10 Horizontal distributions of $\mathbf{a}, \mathbf{f}$ diabatic heating, $\mathbf{b}, \mathbf{g}$ horizontal temperature advection, $\mathbf{c}, \mathbf{h}$ adiabatic heating, and $\mathbf{d}, \mathbf{i}$ air temperature (units: K) at $925 \mathrm{hPa}$; and $\mathbf{e}, \mathbf{j}$ upward surface sensible heating flux (units: $\mathrm{W} \mathrm{m}^{-2}$ ) in the pre-onset $(\mathbf{a}-\mathbf{e})$ and post-onset $(\mathbf{f}-\mathbf{j})$ stages.

Units are $\mathrm{K} \mathrm{day}^{-1}$ in $(\mathbf{a}-\mathbf{c})$ and $(\mathbf{f}-\mathbf{h})$. All calculations are based on the ERA-Interim dataset. Gray shading denotes topography. The ocean portion in the box surrounded by dashed lines is the defined MOB region

over Indochina Peninsula where the pre-monsoon rainfall takes place (Fig. 10d). The surface sensible heat flux is strong over land but weak or even negative over ocean in this period (Fig. 10e).

However, such equilibrium is changed in the post-onset period (Fig. 10f-h). The descent is still located over the Arabian Sea, where the adiabatic heating, together with relatively weak warm temperature advection, balances the local diabatic cooling. Over the MOB region, the diabatic cooling near the surface is due mainly to the enhanced negative sensible heating (Fig. 10f, j), and is balanced by the adiabatic warming due to the local descent after the BOB summer monsoon onset (Figs. 4a, 10h). To the west of $\mathrm{MOB}$ region there is stronger large-scale sinking over the western Indian Peninsula with little convection. Notice that the land surface sensible heat flux is increased to strengthen 


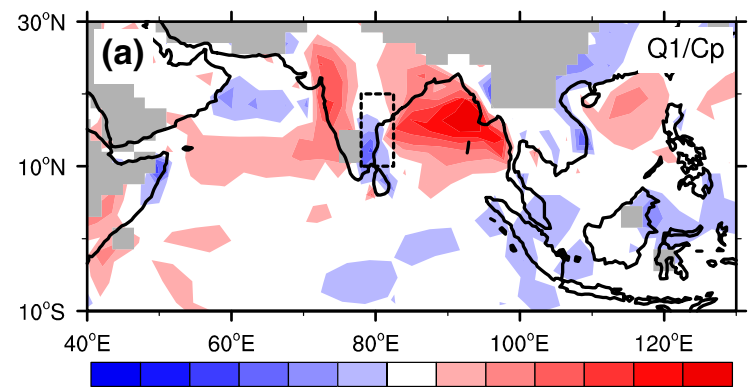

$\begin{array}{llllllllllll}-1.8 & -1.5 & -1.2 & -0.9 & -0.6 & -0.3 & 0.3 & 0.6 & 0.9 & 1.2 & 1.5 & 1.8\end{array}$

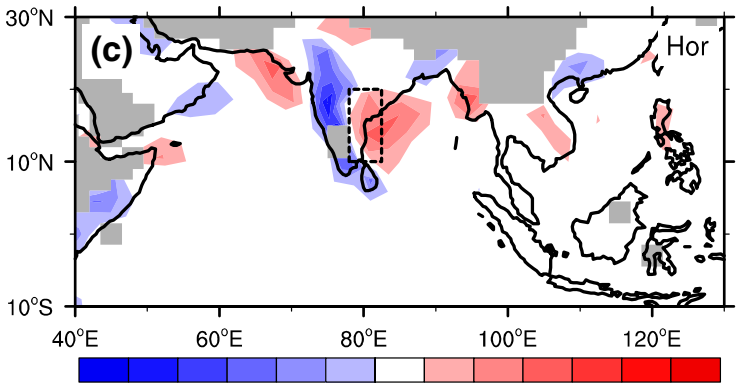

$\begin{array}{llllllllllll}-1.8 & -1.5 & -1.2 & -0.9 & -0.6 & -0.3 & 0.3 & 0.6 & 0.9 & 1.2 & 1.5 & 1.8\end{array}$

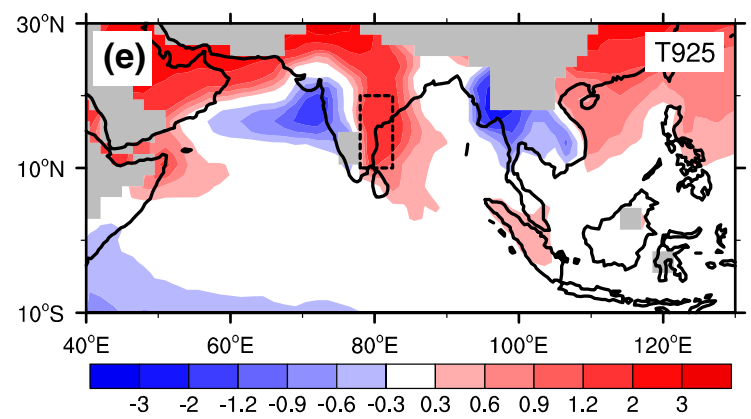

Fig. 11 Onset changes in a diabatic heating, b wind field (units: $\mathrm{m} \mathrm{s}^{-1}$ ), c horizontal temperature advection, $\mathbf{d}$ adiabatic heating, and e air temperature (units: $\mathrm{K}$ ) at $925 \mathrm{hPa}$; and $\mathbf{f}$ upward surface sensi-

the near-surface diabatic heating (Fig. 10f, j), which is balanced by strong cold temperature advection (Fig. 10g) and relatively weak adiabatic cooling (Fig. 10h) in the lower troposphere. The air temperature then increases with the enhanced surface sensible heating over the Indian Peninsula (Fig. 10i). Moreover, to the east of MOB region a deep monsoon convection and strong ascent controls the Indochina Peninsula, where the diabatic heating induced by convective condensation is in equilibrium with adiabatic cooling, even at the near-surface level (Fig. 10f, h). Therefore, during the $\mathrm{BOB}$ onset process, the diabatic effect at $925 \mathrm{hPa}$ is balanced by the adiabatic process over the ocean, including the MOB region, the eastern $\mathrm{BOB}$ and the Arabian Sea, but is compensated by both horizontal temperature advection and the adiabatic effect over the Indian Peninsula to the west of MOB region.

The reason for the strengthened SAT warming and negative sensible heat flux over the MOB region after the $\mathrm{BOB}$ summer monsoon onset can be investigated by the onset
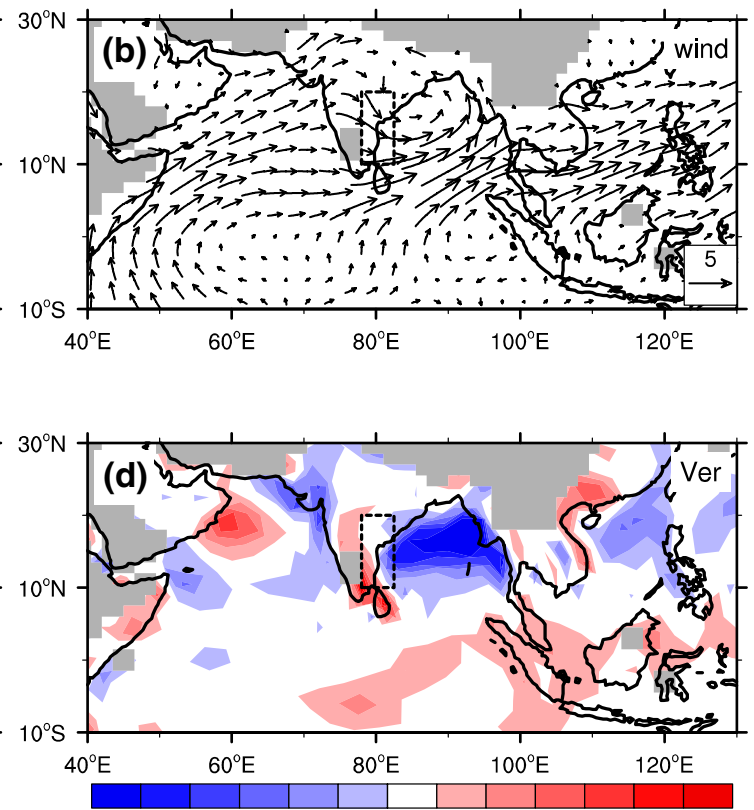

$\begin{array}{lllllllllllll}-1.8 & -1.5 & -1.2 & -0.9 & -0.6 & -0.3 & 0.3 & 0.6 & 0.9 & 1.2 & 1.5 & 1.8\end{array}$

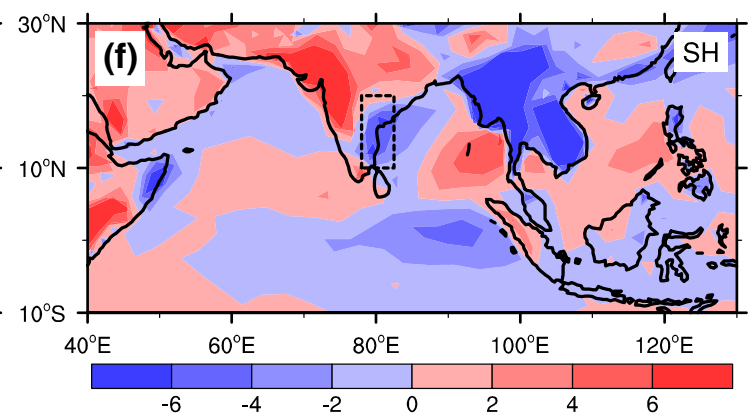

ble heating flux (units: $\mathrm{W} \mathrm{m} \mathrm{m}^{-2}$ ). Units in (a), (c) and (d) are $\mathrm{K} \mathrm{day}^{-1}$. Gray shading denotes topography. The ocean portion in the box surrounded by dashed lines is the defined MOB region

change in each term of Eq. (4) at $925 \mathrm{hPa}$, as displayed in Fig. 11. After the BOB summer monsoon onset, the diabatic heating due to monsoon convection is strengthened over the northeastern $\mathrm{BOB}$ to the east of MOB region, and balanced by adiabatic cooling associated with the enhanced ascent (Fig. 11a, d). Meanwhile, the strengthened anticyclone over the western Indian Peninsula to the west of MOB region (Fig. 11b) enhances the local surface sensible heating (Fig. 11f) to increase the near-surface diabatic heating (Fig. 11a). Subsequently, the enhanced westerly over the Indian Peninsula (Fig. 11b) brings the heated air downstream to the MOB region. Hence, cold and warm temperature advection is strengthened over the Indian Peninsula and the MOB region, respectively (Fig. 11c). In other words, the intensified cold advection tends to balance the stronger diabatic heating over land (Fig. 11a, c); while the reinforced warm advection increases the air temperature over the MOB region, forming the local warm air (Fig. 11e) and producing negative sensible heating 
and diabatic cooling (Fig. 11f, a) which is in equilibrium with the adiabatic warming due to local descent (Fig. 4a, d). The maintenance of negative surface sensible heating over the MOB region after the BOB summer monsoon onset reduces the local APE since heating and temperature there are negatively correlated, and prevents the moist air parcel from uplifting to the LFC, further suppressing monsoon convection over the MOB region. Both the descent in the free atmosphere and the negative sensible heating in the boundary layer contribute to the MOB formation over eastern coastal waters of the Indian Peninsula, where the ASM onset is blocked. However, over the east of the $\mathrm{BOB}$, the enhanced sensible heat flux, with a maximum of $6 \mathrm{~W} \mathrm{~m}^{-2}$ (Figs. 8d, 11f), provides a favorable condition for the uplifting of air parcel, and then facilitates the eastward propagation of monsoon onset. Simultaneously, the upper divergence-pumping associated with the $\mathrm{SAH}$ variation is also conducive to the occurrence of monsoon rainfall over the northeastern $\mathrm{BOB}$; and the vertical coupling between the upper and lower circulation is vital for the formation and maintenance of cyclonic circulation in the lower troposphere over the eastern BOB (Liu et al. 2013). As a result, the monsoon precipitation advances eastward to the Indochina Peninsula and eventually reaches the SCS.

\section{Summary and discussion}

The ERA-Interim reanalysis dataset and latest rainfall products derived from satellite observation were used to investigate the ASM onset process. The results showed that the evolution of monsoon precipitation over India and the Arabian Sea is distinct from that over the BOB and the SCS during ASM onset, i.e., there is a discontinuity between the monsoon onset process over the Indian subcontinent to the Arabian Sea region and that over the BOB and SCS. After ASM onset occurs over the eastern BOB, it continues to advance eastward but cannot propagate westward. Actually, ASM onset propagation is blocked over the eastern coastal waters of Indian Peninsula to form a "MOB" in situ, which is a conspicuous feature during the ASM onset process.

We also discussed the relevant mechanism responsible for the MOB formation. It was elucidated that the atmospheric feedback from the monsoon convective heating during BOB monsoon onset causes the remarkable changes of both the circulation in the free atmosphere and the local air-sea interaction in the boundary layer of the ASM region, and contributes to the MOB formation and ASM onset sequence.

1. After summer monsoon is established over the BOB in early May, the condensation heating released by monsoon convection forces a large-scale circula- tion change. In detail, vertical westerly shear and air descent occurs over the MOB region and the Indian Peninsula, but vertical easterly shear and air ascent appears over the Indochina Peninsula and SCS. In the upper troposphere, the strong condensation heating released by the BOB monsoon convection leads to the strengthening and northwestward migration of the SAH. In the middle and lower troposphere, the IndoBurma trough is generated over the northeastern BOB, which results in the southeastward retreat of the ridgeline of the subtropical anticyclone from $17.5^{\circ} \mathrm{N}$ to $5^{\circ} \mathrm{N}$. The entire pattern of circulation change in the troposphere presents a distinct Gill-type circulation response to the condensation heating over the eastern BOB. Consequently, in the free atmosphere vertical easterly shear develops to the east of the BOB, whereas the wintertime vertical westerly shear is maintained over the MOB region and the India. This large-scale circulation pattern is conducive to the development of air ascent to the east of the BOB and descent to its west, which inhibits the ASM onset from propagating westward directly but allows its eastward propagation.

2. In the boundary layer, the BOB monsoon convection reduces the basin-wide SST through cloud-radiation and wind-evaporation-SST feedback (Xie 1996). Meanwhile, the SAT experiences strong cooling over the eastern BOB due to the monsoon rainfall development, but undergoes remarkable warming over the MOB region ascribed to the strong warm temperature advection from the Indian subcontinent. Consequently, the positive sensible heating over the area east of the central BOB is increased. This helps maintain the surface cyclonic circulation and air ascent in conjunction with the upper-pumping associated with the SAH evolution, and is thus favorable for the eastward expansion of monsoon rainfall to the SCS. Meanwhile, the negative sensible heating develops over the MOB region, which reduces the local APE, prevents the moist air parcel from uplifting to the LFC, and then suppresses the development of monsoon convection. Consequently, monsoon convection cannot be triggered, and summer monsoon rainfall is suppressed to generate the MOB to the west of the BOB monsoon convection.

Although ASM onset cannot advance westward from the BOB to India and the Arabian Sea directly, monsoon convection over the BOB and SCS can facilitate Indian summer monsoon onset indirectly via generating zonal asymmetric instability of the SAH (Liu et al. 2007) and producing divergence-pumping over the Arabian Sea in the upper troposphere (Wu et al. 2013; Zhang et al. 2014). From this viewpoint, the summer monsoon onsets over 
the BOB, SCS and India should be considered as an opendissipative integral process controlled by complex landair-sea interaction, including the influence of large-scale mountain ranges.

Acknowledgments We appreciate the two anonymous reviewers' constructive comments. This study was jointly supported by the Chinese Academy of Sciences (XDA11010402), the MOST program (2010CB950403 and 2012CB417203), the National Science Foundation of China (40925015 and 41275088), the Project funded by China Postdoctoral Science Foundation (2013M540128), the Program for Changjiang Scholars and Innovative Research Team in University (PCSIRT) and the Project Funded by the Priority Academic Program Development of Jiangsu Higher Education Institutions (PAPD).

Open Access This article is distributed under the terms of the Creative Commons Attribution License which permits any use, distribution, and reproduction in any medium, provided the original author(s) and the source are credited.

\section{References}

Abe M, Hori M, Yasunari T, Kitoh A (2013) Effects of the Tibetan Plateau on the onset of the summer monsoon in South Asia: the role of the air-sea interaction. J Geophys Res Atmos 118:1760-1776

Ananthakkrishnan R, Soman MK (1988) The onset of the south-west monsoon over Kerala: 1901-1980. J Climatol 8:283-296

Chan JCL, Wang Y, Xu J (2000) Dynamic and thermodynamic characteristics associated with the onset of the 1998 South China Sea summer monsoon. J Meteorol Soc Jpn 78:367-380

Chen TC, Chen JM (1995) An observational study of the South China Sea monsoon during the 1979 summer: onset and life cycle. Mon Weather Rev 123:2295-2318

Dee DP, Uppala SM, Simmons AJ et al (2011) The ERA-Interim reanalysis: configuration and performance of the data assimilation system. Q J R Meteorol Soc 137:553-597

Ding YH, Chan JCL (2005) The East Asian summer monsoon: an overview. Meteorol Atmos Phys 89:117-142

Eady ET (1950) The cause of general circulation of atmosphere. Cent Proc R Meteorol Soc 156-172

Gadgil S (2003) The Indian monsoon and its variability. Annu Rev Earth Planet Sci 31:429-467

Gadgil S, Sajani S (1998) Monsoon precipitation in the AMIP runs. Clim Dyn 14:659-689

Gill AE (1980) Some simple solutions for heat-induced tropical circulation. Q J R Meteorol Soc 106:447-462

Goswami BN (2005) South Asian monsoon. In: Lau WKM, Waliser DE (eds) Intraseasonal variability in the atmosphere-ocean climate system. Springer-Praxis, London, pp 19-61

Goswami BN, Mohan RSA (2001) Intra-seasonal oscillations and inter-annual variability of the Indian summer monsoon. J Clim 14:1180-1198

Huffman GJ, Adler RF, Morrissey MM et al (2001) Global precipitation at one-degree daily resolution from multi-satellite observations. J Hydrometeor 2:36-50

Hung CW, Yanai M (2004) Factors contributing to the onset of the Australian summer monsoon. Q J R Meteorol Soc 130:739-758

Hung CW, Liu XD, Yanai M (2004) Symmetry and asymmetry of the Asian and Australian summer monsoons. J Clim 17:2413-2426

Kalnay E, Kanamitsu M, Kistler R et al (1996) The NCEP/NCAR 40-year reanalysis project. Bull Am Meteorol Soc 77:437-471

Krishnamurti TN, Ardanuy P, Ramanathan Y et al (1981) On the onset vortex of the summer monsoon. Mon Weather Rev 109:344-363
Lau KM, Yang S (1997) Climatology and interannual variability of the Southeast Asian summer monsoon. Adv Atmos Sci 14:141-162

Lau KM, Wu HT, Yang S (1998) Hydrologic processes associated with the first transition of the Asian summer monsoon: a pilot satellite study. Bull Am Meteorol Soc 79:1871-1882

Li CF, Yanai M (1996) The onset and interannual variability of the Asian Summer Monsoon in relation to land-sea thermal contrast. J Clim 9:358-375

Liebmann B, Smith CA (1996) Description of a complete (interpolated) outgoing longwave radiation dataset. Bull Am Meteorol Soc 77:1275-1277

Liu YM, Chan JCL, Mao JY, Wu GX (2002) The role of Bay of Bengal convection in the onset of the 1998 South China Sea summer monsoon. Mon Weather Rev 130:2731-2744

Liu YM, Hoskins BJ, Blackburn M (2007) Impact of Tibetan orography and heating on the summer flow over Asia. J Meteorol Soc Jpn 85B:1-19

Liu BQ, Wu GX, Mao JY, He JH (2013) Genesis of the South Asian high and its impact on the Asian Summer monsoon onset. J Clim 26:2976-2991

Mak M, Kao CYJ (1982) An instability study of the onset-vortex of the southwest monsoon, 1979. Tellus 34:358-368

Mao JY, Wu GX (2007) Interannual variability in the onset of summer monsoon over the eastern Bay of Bengal. Theor Appl Climatol $89: 155-170$

Mao JY, Wu GX (2011) Barotropic process contributing to the formation and growth of tropical cyclone Nargis. Adv Atmos Sci 28:483-491

Mao JY, Wu GX, Liu YM (2003) Study on the variation in the configuration of subtropical anticyclone and its mechanism during seasonal transition-Part I: Climatological features of subtropical high structure. Acta Meteorol Sin 17:274-286

McBride JL, Frank WM (1999) Relationships between stability and monsoon convection. J Atmos Sci 56:24-36

Prasad VS, Hayashi T (2005) Onset and withdrawal of Indian summer monsoon. Geophys Res Lett. doi:10.1029/2005GL023269

Qian YF, Wang SY, Shao H (2001) A possible mechanism effecting the earlier onset of southwesterly monsoon in the South China Sea compared to the Indian monsoon. Meteorol Atmos Phys 76:237-249

Saha S, Saha K (1980) A hypothesis on onset, advance and withdrawal of the Indian summer monsoon. PAGeoph 118:1066-1075

Sobel AH, Yuter SE, Bretherton CS, Kiladis GN (2004) Large-scale meteorology and deep convection during TRMM KWAJEX. Mon Weather Rev 132:422-444

Srinivasan J, Gadgil S, Webster PJ (1993) Meridional propagation of large-scale monsoon convective zones. Meteorol Atmos Phys 52:15-35

Tanaka M (1992) Intraseasonal oscillation and the onset and retreat dates of the summer monsoon over the east, southeast and western north Pacific region using GMS high cloud amount data. J Meteorol Soc Jpn 70:613-629

Taniguchi K, Koike T (2006) Comparison of definitions of Indian summer monsoon onset: better representation of rapid transitions of atmospheric conditions. Geophys Res Lett. doi:10.1029/200 5GL024526

Tao SY, Chen LX (1987) A review of recent research on the East Asian summer monsoon in China. In: Chang CP, Krishnamurti TN (eds) Monsoon meteorology. Oxford University Press, London, pp 60-92

Thompson RM Jr, Payne SW, Recker EE, Reed RJ (1979) Structure and properties of synoptic-scale wave disturbances in the intertropical convergence zone of the eastern Atlantic. J Atmos Sci 36:53-72

Tian Y, Wang Q (2010) Definition of the South China Sea summer monsoon onset. Chin J Oceanol Limnol 28:1281-1289 
Tong HW, Chan JCL, Zhou W (2009) The role of MJO and mid-latitude fronts in the South China Sea summer monsoon onset. Clim Dyn 33:827-841

Vinayachandran PN, Shankar D, Kuria J, Durand F, Shenoi SSC (2007) Arabian Sea mini warm pool and monsoon onset vortex. Curr Sci 93:203-214

Wang B (2006) The Asian monsoon. Springer-Praxis, London 788 pp

Wang B, LinHo (2002) Rainy Season of the Asian-Pacific summer monsoon. J Clim 15:386-398

Wang B, Wu RG (1997) Peculiar temporal structure of the South China Sea summer monsoon. Adv Atmos Sci 14:177-194

Wang B, Zhang Y, Lu MM (2004) Definition of South China Sea monsoon onset and commencement of the East Asia summer monsoon. J Clim 17:699-710

Wang B, Huang F, Wu ZW et al (2009a) Multi-scale climate variability of the South China Sea monsoon: a review. Dyn Atmos Ocean 47:15-37

Wang B, Ding QH, Joseph PV (2009b) Objective definition of the Indian summer monsoon onset. J Clim 22:3303-3316

Webster PJ, Yang S (1992) Monsoon and ENSO: selectively interactive systems. Q J R Meteorol Soc 118:877-926

Webster PJ, Magaña VO, Palmer TN, Shukla J, Tomas RA, Yanai M, Yasunari T (1998) Monsoons: processes, predictability, and the prospects for prediction. J Geophys Res 103:14451-14510

Wu RG (2010) Subseasonal variability during the South China Sea summer monsoon onset. Clim Dyn 34:629-642

Wu GX, Zhang YS (1998) Tibetan Plateau forcing and the timing of the monsoon onset over South Asian and the South China Sea. Mon Weather Rev 126:913-927

Wu GX, Liu YM, Zhang Q et al (2007) The influence of the mechanical and thermal forcing of the Tibetan Plateau on the Asian climate. J Hydrometeorol 8:770-789

Wu GX, Guan Y, Wang TM et al (2011) Vortex genesis over the Bay of Bengal in spring and its role in the onset of the Asian summer monsoon. Sci China Earth Sci 54:1-9

Wu GX, Guan Y, Liu YM et al (2012a) Air-sea interaction and formation of the Asian summer monsoon onset vortex over the Bay of Bengal. Clim Dyn 38:261-279

Wu GX, Liu YM, He B et al (2012b) Thermal controls on the Asian summer monsoon. Sci Rep 2:404. doi:10.1038/srep00404
Wu GX, Duan AM, Liu YM et al (2013) Recent advances in the study on the dynamics of the Asian summer monsoon onset. Chin $\mathbf{J}$ Atmos Sci 37:211-228 (in Chinese)

Xavier PK, Marzin C, Goswami BN (2007) An objective definition of the Indian summer monsoon season and a new perspective on the ENSO-monsoon relationship. Q J R Meteorol Soc 133:749-764

Xie SP (1996) Westward propagation of latitudinal asymmetry in a coupled ocean-atmosphere model. J Atmos Sci 53:3236-3250

Xie SP, Arkin P (1997) Global precipitation: a 17-year monthly analysis based on gauge observations, satellite estimates, and numerical model outputs. Bull Am Meteorol Soc 78:2539-2558

Xie SP, Xie Q, Wang DX, Liu WT (2003) Summer upwelling in the South China Sea and its role in regional climate variations. J Geophys Res 108:3261. doi:10.1029/2003JC001867

$\mathrm{Xu} \mathrm{J}$, Chan JCL (2001) First transition of the Asian summer monsoon in 1998 and the effect of the Tibet-tropical ocean thermal contrast. J Meteorol Soc Jpn 79:241-253

Xu HM, Xie SP, Wang Y et al (2008) Orographic effects on South China Sea summer climate. Meteorol Atmos Phys 100:275-289

Yan JH (2005) Asian summer monsoon onset and advancing process and the variation of the subtropical high. $\mathrm{PhD}$ dissertation, Graduate University of Chinese Academy of Sciences (in Chinese)

Yang XX, Yao TD, Yang WL et al (2012) Isotopic signal of earlier summer monsoon onset in the Bay of Bengal. J Clim 25:2509-2516

Yano J, Emanuel KA (1991) An improved model of the equatorial troposphere and its coupling with the stratosphere. J Atmos Sci 48:377-389

Yoshino MM (1966) Four stages of the rainy season in early summer over East Asia (Part II). J Meteorol Soc Jpn 44:209-217

Zhang YN, Wu GX, Liu YM, Guan Y (2014) Effect of zonal asymmetric instability of potential vorticity on the South Asian high and the India summer monsoon onset. Sci China Earth Sci 57:337-350

Zhou W, Chan JCL (2005) Intraseasonal oscillations and the South China Sea summer monsoon onset. Int J Climatol 25:1585-1609

Zhou W, Chan JCL (2007) ENSO and the South China Sea summer monsoon onset. Int J Climatol 27:157-167 